\title{
Analytic Creep Durability of Rotating Uniform Disks
}

\author{
YURIY NYASHIN * and VICTOR SHISHLYAEV \\ Department of Theoretical Mechanics, Perm Federal Technical University, 29a Komsomolsky Ave., 614600 , \\ GSP-45, Perm, Russia
}

(Received 3 January 1997; Revised 26 November 1997; In final form 29 January 1998)

\begin{abstract}
Turbine disks of aircraft engines in operation are subjected to alternating thermocyclic deformation under high temperatures. Operation gives rise to sufficiently high stresses and subsequent creep damaging effects.

In this paper we suggest an approach for describing creep rupture of a simple rotating disk due to the accumulation of creep induced microdefects. The dissipated energy of the creep deformation is considered as the measure of material damage.

The lifetime of the disk can be predicted on the basis of this approach. Both crack initiation and damage propagation to complete rupture of a disk are calculated. The analytic results can be compared to known experimental data. The derived algorithm can be applied to estimate the lifetime of real machinery components when creep deformations are dominant.
\end{abstract}

Keywords: Creep rupture, Damage, Durability, Gas turbine, Lifetime, Microdefects

\section{INTRODUCTION}

Turbine disks are important elements of aircraft engines. The strength and lifetime of disks determine an engine's ability to reach its required service operating parameters including durability and reliability.

In operation, disks of turbojet engines are subjected to alternating thermocyclic deformation under high temperatures. The basic components of disk loading are:

- centrifugal forces caused by rotation;
- nonstationary temperature field (essentially inhomogeneous along the radial coordinate);

- pressure differential on the disk web;

- clamping forces caused by the rotor assemblage;

- radial forces from the disk blading.

The joint action of the aforementioned factors can lead to high stresses and subsequent creep effects. Experimental data obtained by Sosnin et al. (1986) allow to estimate the time for creep deformation development up to the value of $0.5 \%$ as $10^{1}-10^{2} \mathrm{~h}$ within the stress concentration zones (disk fillets, blade roots and shaft splines). Therefore we can state

*Corresponding author. Tel.: (3422) 39-17-02. E-mail: nyashin@tmex.icmm.perm.su. 
that creep deformation is a dominant factor of material damage in comparison to elastic one.

\section{PHENOMENOLOGICAL DESCRIPTION OF DAMAGE AND RUPTURE}

The prevailing methods of engineering design are based on the various theories of plastic flow and analogous creep models. At the same time accumulation of the static and cyclic defects leads to untimely fracture of the disks. Therefore the durability ought to be calculated on the basis of exact estimation of stress and strain fields, variation of material properties due to the cyclic loading and account of material damage.

The phenomenological approach to the description of creep rupture was suggested by Kachanov (1958). He introduced the scalar function $\psi: 1 \geq \psi \geq 0$, characterizing the damage (accumulation of microscopic cracks and material defects) within the investigated domain. For initial (undamaged) state $\psi=1$; in operation, the function $\psi$ is decreasing down to the zero value. The value $\psi=0$ corresponds to material fracture and can be considered as the fracture criterion. To obtain the durability it is necessary to supplement the boundary-value problem by equation describing damage development with time (the so-called damage kinetics equation).

Later different models were suggested by Rabotnov (1969), Ilyushin and Pobedria (1970), Kolmogorov (1970), Murakami (1983), Lemaitre and Chaboche (1985), Sosnin et al. (1986), Chaboche (1988) and Baltov (1993) in order to describe material fracture in the process of unreversible deformation of material. Generally speaking, such models ought to correlate with applied model of deformation and reflect kinetics of damage development at the points of the investigated body. Usually the fracture criterion is formulated on the basis of deformation-type or energy-type criteria. As a result of aforementioned model representations, investigation of construction behavior consist in step-by-step integration of the constitutive relations for different levels of external loading.

In this paper we consider the problem of description of the rupture of thin isotropic disks in the framework of constitutive relations of the creep theory. We ought to mention that similar problem was solved by Kachanov (1974) for uniformly distributed tensile load acting along external contour of the disk. In this paper we consider the centrifugal forces caused by rotation as the load factor in an attempt to more closely simulate the operation of aircraft turbine engines.

\section{STATEMENT OF THE PROBLEM}

Let us consider a rotating disk with an internal axial hole. Initial radius of the internal hole is denoted by $a_{0}$, an external disk radius by $b_{0}$ (see Fig. 1). A rotation rate of $\omega$ was held constant.

We assume the initial thickness of the disk $h$ to be small and independent of radial coordinate $r$. This assumption seems to be correct for thin turbine disks and deflectors. It means that plane stress model can be applied and consequently

$$
\sigma_{z}=0 .
$$

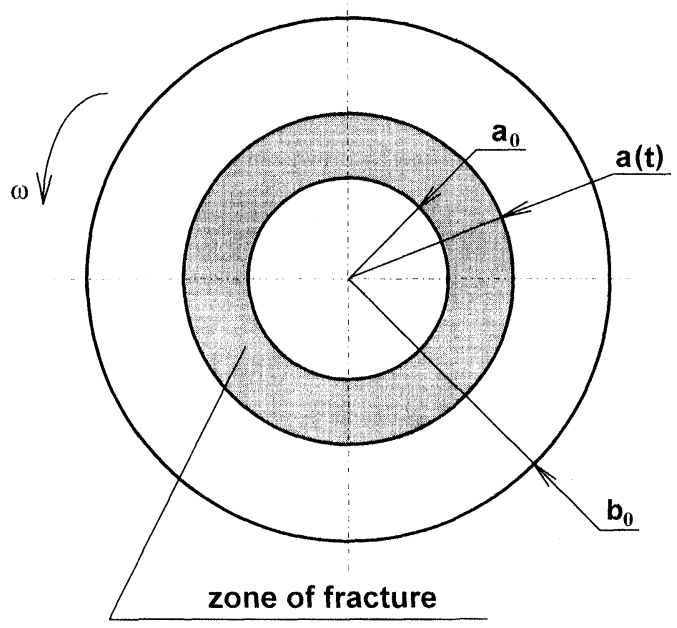

FIGURE 1 Initial configuration of the investigated domain and fracture development from the surface of internal hole. 
Radial and tangential strain rates can be written in the following form

$$
\xi_{r}=\frac{\partial v}{\partial r}, \quad \xi_{\varphi}=\frac{v}{r},
$$

where $v(r, t)$ is radial velocity of the disk particles. The axial strain rate can be found from the incompressibility condition

$$
\xi_{z}=-\left(\xi_{r}+\xi_{\varphi}\right)
$$

The equilibrium equation for a rotating disk is written according to Timoshenko and Goodier (1951):

$$
\frac{\partial}{\partial r}\left(r \sigma_{r}\right)-\sigma_{\varphi}=K r^{2}
$$

with $K=-d \omega^{2}, d$-material density. The boundary conditions at the contour of the disk

$$
\begin{aligned}
& \sigma_{r}[r=a(t)]=0, \\
& \sigma_{r}[r=b(t)]=0,
\end{aligned}
$$

where $a(t)$ - radius of internal hole, $a(t=0)=a_{0}$, $b(t)$ - external disk radius, $b(t=0)=b_{0}$.

To simplify the analysis we apply the scheme of maximal tangential stress with associated flow law. Let us assume, that

$$
\sigma_{\varphi}>\sigma_{r}>0
$$

for every internal point of the disk. Then in accordance with the suggested flow law

$$
\xi_{r}=0,
$$

and consequently,

$$
\xi_{z}=-\xi_{\varphi}
$$

Generally speaking, Kachanov (1960) shows that the interior of a disk can experience zones with different flow rules. In this paper we consider the variant described by the inequality (6) only. Further we show that definite restriction on the initial sizes follows from this assumption. Figure 2 presents the Treska prism cross-section by the plane $\sigma_{z}=0$ and possible flow directions.

From Eq. (7) it follows that $\partial v / \partial r=0$. Consequently, the radial velocity of the disk particles depends upon the time only:

$$
v=v_{0}(t), \quad \text { where } v_{0}=v\left(a_{0}, t\right),
$$

and tangential strain rate is determined as

$$
\xi_{\varphi}=\frac{v_{0}}{r}
$$

This corresponds to the segment $\mathrm{A}_{11} \mathrm{~A}_{12}$ at the Fig. 2.

Let us assume the Hoff law as the constitutive relation of creep

$$
\xi=B \sigma^{m}
$$

where $B>0, m \geq 1$ are constants for the fixed temperature. Kachanov (1960) shows that this type of constitutive law gives the best approximation of experimental creep curve for investigated class of materials.

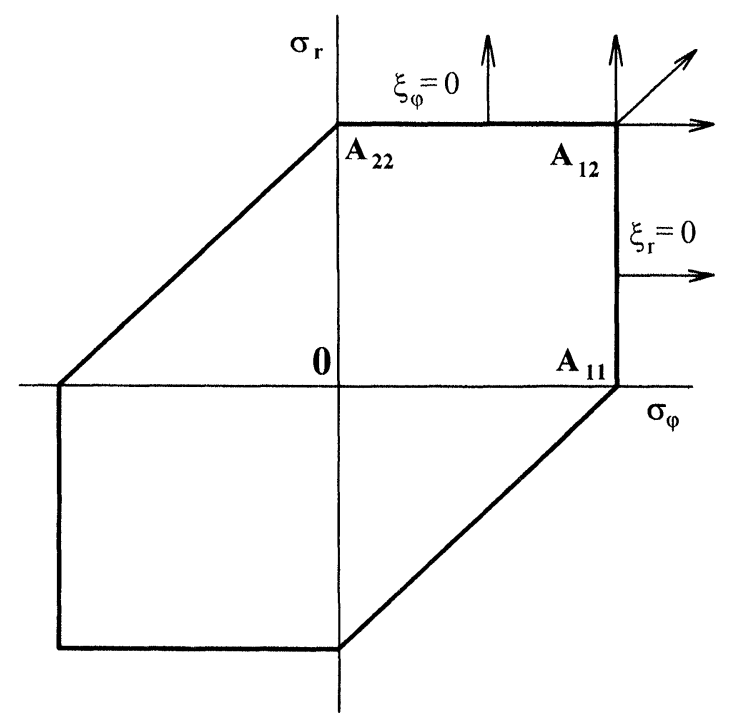

FIGURE 2 Creep flow surface cross-section by the plane $\sigma_{z}=0$ and possible flow directions. 
According to assumptions (7) and (8), we can overwrite Eq. (11) in terms of maximal tangential stress $\tau_{\max }$ and tangential strain rate $\gamma_{\max }$. For uniaxial stress state $\tau_{\max }=\frac{1}{2}\left|\sigma_{1}-\sigma_{3}\right|=\sigma / 2$ and $\gamma_{\max }=\left|\xi_{1}-\xi_{3}\right|=\frac{3}{2} \xi$. Therefore:

$$
\gamma_{\max }=3 \cdot 2^{m-1} B \tau_{\max }^{m} .
$$

For investigated multiaxial flow $\tau_{\max }=$ $\frac{1}{2}\left|\sigma_{\varphi}-\sigma_{z}\right|=\sigma_{\varphi} / 2, \quad \gamma_{\max }=\left|\xi_{\varphi}-\xi_{z}\right|=2 \xi_{\varphi} \quad$ and consequently:

$$
\xi_{\varphi}=\frac{3}{4} B \sigma_{\varphi}^{m}
$$

Finally, components of the strain rate tensor can be found according to the following formulae

$$
\xi_{\varphi}=B_{1} \sigma_{\varphi}^{m}, \quad \xi_{r}=0, \quad \xi_{z}=-B_{1} \sigma_{\varphi}^{m},
$$

where $B_{1}=\frac{3}{4} B$ - constant coefficient.

\section{STRESS FIELD CALCULATION}

Resolving Eq. (14) with respect to $\sigma_{\varphi}$ and integrating the equilibrium equation (4) over the radial coordinate $r$ taking account of the boundary conditions (5), we obtain the stress tensor components:

$$
\begin{aligned}
\sigma_{r}= & \frac{K\left(r^{3}-a^{3}\right)}{3 r}+\frac{K\left(a^{3}-b^{3}\right)}{3 r\left(b^{1-\mu}-a^{1-\mu}\right)} \\
& \times\left(r^{1-\mu}-a^{1-\mu}\right), \\
\sigma_{\varphi}= & \frac{K(1-\mu)}{3} \frac{\left(a^{3}-b^{3}\right)}{\left(b^{1-\mu}-a^{1-\mu}\right)} r^{-\mu},
\end{aligned}
$$

where $\mu=1 / \mathrm{m}$.

Further we need to verify the hypothesis (6). This assumption means that at every internal point of the disk the following inequalities ought to be valid

$$
\begin{gathered}
\sigma_{\varphi}-\sigma_{r}>0, \quad \forall r \in(a, b), \\
\sigma_{r}>0, \quad \forall r \in(a, b) .
\end{gathered}
$$

Taking account of $K<0, b>a$ and $r>a, \forall r \in$ $(a, b)$, we can show that inequality (16.1) is equivalent to

$$
a^{1-\mu}>\mu r^{1-\mu} .
$$

Relation (17) can be forced because $r_{\max }=b$ :

$$
a^{1-\mu}>\mu b^{1-\mu} .
$$

Finally, assumption (16.1) leads to the following restriction on the disk parameters

$$
m>\left[\frac{b}{a}\right]^{\frac{m-1}{m}} \text { or }\left[\frac{b}{a}\right]<m^{\frac{m}{m-1}}, \quad m>1 .
$$

It is easy to show that inequality (16.2) is valid for any values of $a$ and $b$. This means that if geometry of the disk satisfies restriction (19), assumption (6) is valid and stress tensor components are determined by the Eqs. (15).

\section{ACCOUNT OF DAMAGE DEVELOPMENT}

To describe the damage accumulation process we apply the energy variant of the creep theory suggested by Sosnin et al. (1986). It was found that the value of dissipated energy of creep deformation

$$
W=\int_{0}^{\varepsilon} \sigma_{i j} \mathrm{~d} \varepsilon_{i j}
$$

is constant at the moment of fracture for a wide class of materials (e.g., for $\alpha$ and $\alpha+\beta$ titanium alloys). In Eq. (20) $\sigma_{i j}$ designates the stress tensor components, $\varepsilon_{i j}$ designates the creep strain tensor components $(i, j=\overline{1,3})$. This assumption was verified experimentally for various temperature regimes and deformation rates. Therefore we can consider the value of dissipated energy $W$ as the measure of accumulated damage.

Let us introduce the scalar function $\psi$ associated with the dissipated energy:

$$
\psi=1-\frac{W}{W_{*}},
$$


where $W_{*}$ is the critical value of the dissipated energy corresponding to material fracture. For initial (undamaged) state $\psi=1$. The value $\psi=0$ corresponds to critical accumulation of microscopic defects and material fracture. Thus, the function $\psi$ is normalized $(1 \geq \psi \geq 0)$ and nondecreasing: $\mathrm{d} \psi / \mathrm{d} t \leq 0$.

Sosnin et al. (1986) shows that damage development for unhardening materials at the steady-state stage of creep flow can be approximated by the exponential law:

$$
\begin{aligned}
& \frac{\mathrm{d} W}{\mathrm{~d} t}=\frac{D \sigma_{\max }^{m}}{\left(W_{*}-W\right)^{n}} \quad \text { for } \sigma_{\max } \geq 0, \\
& \frac{\mathrm{d} W}{\mathrm{~d} t}=0 \quad \text { for } \sigma_{\max }<0
\end{aligned}
$$

where $\sigma_{\max }$ is the maximal principal stress, $D>0$, $n \geq 0$ - material constants; $m$ - the power index from Eq. (11).

In terms of the measure $\psi$ we can formulate the damage kinetics equations as follows

$$
\begin{aligned}
& \frac{\mathrm{d} \psi}{\mathrm{d} t}=-\frac{A \sigma_{\max }^{m}}{\psi^{n}} \quad \text { for } \sigma_{\max } \geq 0, \\
& \frac{\mathrm{d} \psi}{\mathrm{d} t}=0 \text { for } \sigma_{\max }<0,
\end{aligned}
$$

where $A=D / W_{*}^{n+1}$. The constants $A$ and $n$ ought to be found from the experiments on the creep rupture strength.

To find the durability of the disk we need to integrate Eqs. (23) with respect to the found stress fields.

According to assumption (6) the tangential stress is maximal for all internal points of the disk at initial moment: $\sigma_{\max }=\sigma_{\varphi}>0, \forall r \in\left(a_{0}, b_{0}\right)$. Because of $\max _{r}\left[\sigma_{\varphi}(r)\right]=\sigma_{\varphi}\left(a_{0}\right), \forall r \in\left(a_{0}, b_{0}\right)$, we assume that fracture starts from the surface of internal hole of the disk. Consequently, in the process of fracture external radius of the disk is constant, while the internal radius value depends upon the time:

$b=b_{0}=$ Const $, \quad a=a(t), \quad r \in\left(a(t), b_{0}\right)$.
Let us introduce the dimensionless variables:

$$
\frac{r}{b_{0}}=\rho, \quad \frac{a}{b_{0}}=\alpha, \quad \frac{a_{0}}{b_{0}}=\alpha_{0} .
$$

Then Eq. (15.2) can be written taking account of (24)

$$
\begin{gathered}
\sigma_{\varphi}=s(\alpha) \rho^{-\mu}, \\
\text { where } s(\alpha)=\frac{K(1-\mu)}{3} \frac{\left(\alpha^{3}-1\right)}{\left(1-\alpha^{1-\mu}\right)} b_{0}^{2} .
\end{gathered}
$$

By separation of variables in Eq. (23.1) we can describe the damage accumulation process as follows

$$
\int_{1}^{\psi} \psi^{n} \mathrm{~d} \psi=-A \int_{0}^{t} \sigma_{\max }^{m} \mathrm{~d} t
$$

At the crack initiation stage (while $t<t_{\mathrm{I}}$ ) the stress tensor components are constant:

$$
\sigma_{\max }=\sigma_{\varphi}=s\left(\alpha_{0}\right) \alpha_{0}^{-\mu}
$$

because $a=a_{0}=$ Const and $\alpha=\alpha_{0}=\rho$.

Moreover, the value of principal stress $\sigma_{\max }$ is time independent. Consequently, if suppose $\psi=0$ in Eq. (27) we can obtain the following simple relation for the value of $t_{\mathrm{I}}$

$$
t_{\mathrm{I}}=\frac{1}{A(n+1) \sigma_{\max }^{m}}=\frac{\alpha_{0}}{A(n+1) s^{m}\left(\alpha_{0}\right)}
$$

The time $t_{\mathrm{I}}$ corresponds to the critical accumulation of damage on the contour of the internal hole. From a physical point of view it corresponds to appearance of macroscopic cracks and material defects. Further (when $t \geq t_{\mathrm{I}}$ ) the disk fracture develops in a radial direction towards the external contour. This process is accompanied with variation of disk geometry.

The fracture criterion for any point of the disk can be formulated as

$$
A(n+1) \int_{0}^{t} \sigma_{\max }^{m}(\tau) \mathrm{d} \tau=1
$$


Let us note that in the process of fracture progression, the internal radius of the disk is increasing $\left(a(t) \geq a_{0}\right)$, and, consequently, restriction (19) and assumption (6) are valid. It means that Eqs. (15) are correct at any time and tangential stress corresponds to the maximal principal stress always:

$$
\begin{aligned}
& \sigma_{\max }=\sigma_{\varphi}=s(\alpha) \rho^{-\mu}, \\
& A(n+1) \int_{0}^{t} s^{m}(\alpha) \rho^{-1} \mathrm{~d} \tau=1 .
\end{aligned}
$$

In Eq. (31) $s(\alpha)=s[\alpha(\tau)]$ and the value $\rho$ is independent of the load history: $\rho=\alpha(t)$. Therefore

$$
\frac{A(n+1)}{\alpha(t)} \int_{0}^{t} s^{m}[\alpha(\tau)] \mathrm{d} \tau=1
$$

Differentiating Eq. (32) with time we obtain the following equation of fracture edge movement

$$
\frac{\mathrm{d} \alpha}{\mathrm{d} t}=A(n+1) s^{m}(\alpha)
$$

Further, taking account of (29) and integrating the equation of fracture edge movement (33) with initial condition $\alpha=\alpha_{0}$ for $t=t_{\mathrm{I}}$, we obtain

$$
\frac{t}{t_{\mathrm{I}}}-1=\frac{1}{\alpha_{0}} \int_{\alpha_{0}}^{\alpha}\left[\frac{\left(\alpha_{0}^{3}-1\right)\left(1-\alpha^{1-\mu}\right)}{\left(\alpha^{3}-1\right)\left(1-\alpha_{0}^{1-\mu}\right)}\right]^{m} \mathrm{~d} \alpha
$$

The time for complete fracture of the disk $t_{*}$ can be found from Eq. (34) if suppose $\alpha=1$ :

$$
\frac{t_{*}}{t_{\mathrm{I}}}=1+\frac{1}{\alpha_{0}} \int_{\alpha_{0}}^{1}\left[\frac{\left(\alpha_{0}^{3}-1\right)\left(1-\alpha^{1-\mu}\right)}{\left(\alpha^{3}-1\right)\left(1-\alpha_{0}^{1-\mu}\right)}\right]^{m} \mathrm{~d} \alpha
$$

\section{NUMERICAL ANALYSIS AND DISCUSSION}

As an illustration we try to find the durability of the disk made of $\alpha+\beta$ titanium alloy VT9 (5.8-7.0\% $\mathrm{Al}, 2.8-3.8 \% \mathrm{Mo}, 0.8-2.5 \% \mathrm{Zr}, 0.20-0.36 \% \mathrm{Si})$ with the following parameters

- rotation rate $\omega=11600 \mathrm{rpm}$;

- initial radius of internal hole $a_{0}=75 \mathrm{~mm}$;

- external radius of the disk $b_{0}=237.9 \mathrm{~mm}$;

- material density $d=4490 \mathrm{~kg} / \mathrm{m}^{3}$.

This alloy is widely used to manufacture disks, deflectors, disk blades, fasteners and body details of aircraft gas turbine engines. The ultimate stress $\sigma_{U}$, yield limit $\sigma_{Y}$ and creep limit $\sigma_{100}$ for titanium alloy VT9 are presented in the Table I.

Aforementioned sizes and rotation rate correspond to the real parameters of a turbine disk of an aircraft gas turbine engine during take-off. According to experimental data the temperature of the disk hub is equal to $452^{\circ} \mathrm{C}$, while the rim temperature is equal to $608^{\circ} \mathrm{C}$. The values of material constants applied for damage description are shown in Table II. The values are calculated on the basis of the experimental data obtained by Sosnin et al. (1986). It is easy to verify that restriction (19) is valid for both of the investigated regimes.

Figure 3 shows the fracture edge position versus dimensionless time for the temperature of $600^{\circ} \mathrm{C}$ $\left(m=3, \alpha_{0}=0.315\right)$. The fracture time was calculated by numerical integrating of Eq. (34) by the Gauss method. The figure shows that the fracture develops with relatively slow speed at initial stage. Then the fracture rate increases significantly.

TABLE I Mechanical properties for titanium alloy VT9

\begin{tabular}{lrrc}
\hline Temperature, ${ }^{\circ} \mathrm{C}$ & $\sigma_{U}, \mathrm{MPa}$ & $\sigma_{Y}, \mathrm{MPa}$ & $\sigma_{100}, \mathrm{MPa}$ \\
\hline 20 & 1127.76 & 1010.08 & - \\
400 & 833.57 & 706.08 & - \\
500 & 784.53 & 647.24 & 637.43 \\
550 & 764.92 & 608.01 & 441.30 \\
600 & 706.08 & 539.37 & 225.55 \\
\hline
\end{tabular}

TABLE II Material constants for titanium alloy VT9

\begin{tabular}{lccc}
\hline Temperature, ${ }^{\circ} \mathrm{C}$ & $n$ & $m$ & $A, \mathrm{MPa}^{-m} \mathrm{~s}^{-1}$ \\
\hline 550 & 2.33 & 4.0 & $1.7733 \cdot 10^{-9}$ \\
600 & 2.33 & 3.0 & $1.3377 \cdot 10^{-7}$ \\
\hline
\end{tabular}




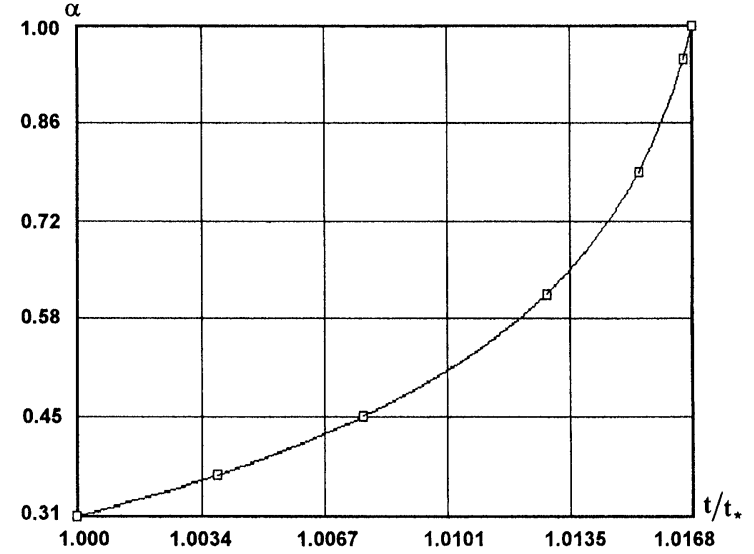

FIGURE 3 Movement of the fracture edge.

Complete fracture of the disk (i.e. the state when the fracture edge reaches external radius) corresponds to the moment of $t_{*}=1.017 t_{\mathrm{I}}$.

The calculation of crack initiation time according with Eq. (30) shows the following results:

$$
\begin{aligned}
& t_{\mathrm{I}}=82845 \mathrm{~h} \text { at } 550^{\circ} \mathrm{C} ; \\
& t_{\mathrm{I}}=48600 \mathrm{~h} \text { at } 600^{\circ} \mathrm{C} .
\end{aligned}
$$

The obtained solution can be applied to estimate the lifetime of machinery components when creep effects are dominant. Use of an overly simplified disk geometry makes the problem tractable from an analytic point of view, but the presented model of damage development can be realized numerically as an element of stress field calculation.

Turbine disks in aeronautical gas turbines are life limited not by creep only, but by low-cycle fatigue too due to each start-stop cycle of loading. This would cause a reversal in stress direction within a local region (the inner bore in the present problem) and re-initiation of primary creep upon the start of the second flight, etc. Therefore the model can be applied for some long-range flights (e.g. supersonic cruise of transcontinental flights) when the contribution of the creep portion to the overall damage is dominant.

\section{NOMENCLATURE}

$\psi \quad$ damage function

$a, b \quad$ internal hole radius and external disk radius

$a_{0}, b_{0} \quad$ initial values of internal hole radius and external disk radius

$\omega \quad$ rotation rate

$h \quad$ initial thickness of the disk

$\sigma, \sigma_{i j} \quad$ stress and stress tensor components

$\sigma_{r}, \sigma_{\varphi}, \sigma_{z}$ radial, tangential and axial stresses

$\tau_{\max } \quad$ maximal tangential stress

$\xi \quad$ strain rate

$\xi_{r}, \xi_{\varphi}, \xi_{z} \quad$ radial, tangential and axial strain

rates

$\gamma_{\max } \quad$ maximal tangential strain rate

$v \quad$ radial velocity of the disk particles

$d \quad$ material density

$B, B_{1}, m$ material constants from the creep flow law, Eqs. (11) and (14)

$W \quad$ dissipated energy of creep deformation

$W_{*} \quad$ critical value of the dissipated energy of creep deformation corresponding to material fracture

$\varepsilon, \varepsilon_{i j} \quad$ creep strain and creep strain tensor components

$D, n \quad$ material constants from the damage kinetics equation, Eq. (22)

$\rho, \alpha, \alpha_{0} \quad$ dimensionless variables

$t_{\mathrm{I}} \quad$ time for critical accumulation of damage (time for crack initiation)

$t_{*} \quad$ time for complete fracture of the disk

$\begin{array}{ll}\sigma_{U} & \text { ultimate stress } \\ \sigma_{Y} & \text { yield limit }\end{array}$

$\sigma_{100} \quad$ creep limit

\section{Acknowledgment}

The authors gratefully acknowledge support of this work provided by the Russian Federal Program 'Fundamental Research in the Technical Universities'. 


\section{References}

Baltov, A.I. (1993) Modelling of the induced anisotropy in inelastic bodies, Proc. of the International Seminar MECAMAT '91, Balkema, Rotterdam, pp. 19-26.

Chaboche, J.L. (1988) Continuum damage mechanics. Part I and Part II, ASME Journal of Applied Mechanics, 55, 59-72.

Ilyushin, A.A. and Pobedria, B.E. (1970) Fundamentals of Mathematical Theory of Thermoviscoelasticity, Nauka Publishing, Moscow (in Russian).

Kachanov, L.M. (1958) On the time to failure under creep conditions, Izv. AN SSSR, Otd. Tekhn. Nauk, 8, 26-31 (in Russian).

Kachanov, L.M. (1960) Theory of Creep, Fizmatgiz Publishing, Moscow (in Russian)

Kachanov, L.M. (1974) Fundamentals of Fracture Mechanics, Nauka Publishing, Moscow (in Russian).
Kolmogorov, V.L. (1970) Stress, Strain, Fracture, Metallurgiya Publishing, Moscow (in Russian)

Lemaitre, J. and Chaboche, J.L. (1985) Mécanique des Matériaux Solides, Dunod, Paris.

Murakami, S. (1983) Notion of continuum damage mechanics and its application to anisotropic creep damage theory, ASME Journal of Engineering Materials and Technology, 105, 99-105.

Rabotnov, Yu.N. (1969) Creep Problems in Structural Members North-Holland, Amsterdam.

Sosnin, O.V., Gorev, B.V. and Nikitenko, A.F. (1986) Energy Variant of the Creep Theory, Novosibirsk Institute of Hydrodynamics of Sibirian Branch of the USSR Academy of Sciences, Novosibirsk (in Russian)

Timoshenko, S. and Goodier, J. (1951) Theory of Elasticity, McGraw-Hill Book Co., New York. 


\section{ait \\ ENERGY MATERIALS}

M A N E Y publishing

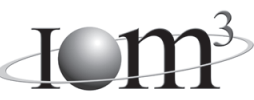

\section{Materials Science \& Engineering for Energy Systems}

Maney Publishing on behalf of the Institute of Materials, Minerals and Mining

The Institute of Materials, Minerals \& Mining

Economic and environmental factors are creating ever greater pressures for the efficient generation, transmission and use of energy. Materials developments are crucial to progress in all these areas: to innovation in design; to extending lifetime and maintenance intervals; and to successful operation in more demanding environments. Drawing together the broad community with interests in these areas, Energy Materials addresses materials needs in future energy generation, transmission, utilisation, conservation and storage. The journal covers thermal generation and gas turbines; renewable power (wind, wave, tidal, hydro, solar and geothermal); fuel cells (low and high temperature); materials issues relevant to biomass and biotechnology; nuclear power generation (fission and fusion); hydrogen generation and storage in the context of the 'hydrogen economy'; and the transmission and storage of the energy produced.

As well as publishing high-quality peer-reviewed research, Energy Materials promotes discussion of issues common to all sectors, through commissioned reviews and commentaries. The journal includes coverage of energy economics and policy, and broader social issues, since the political and legislative context influence research and investment decisions.

\section{CALL FOR PAPERS}

Contributions to the journal should be submitted online at http://ema.edmgr.com

To view the Notes for Contributors please visit: www.maney.co.uk/journals/notes/ema

Upon publication in 2006, this journal will be available via the Ingenta Connect journals service. To view free sample content online visit: www.ingentaconnect.com/content/maney

For further information please contact:

Maney Publishing UK

Tel: +44 (0)113 2497481 Fax: +44 (0)1132486983 Email: subscriptions@maney.co.uk

or

Maney Publishing North America

Tel (toll free): 8662975154 Fax: 6173546875 Email: maney@maneyusa.com

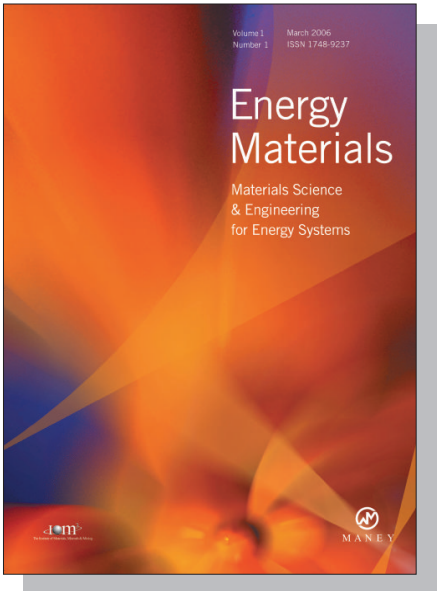

EDITORS

Dr Fujio Abe

NIMS, Japan

Dr John Hald, IPL-MPT, Technical University of Denmark, Denmark

Dr R Viswanathan, EPRI, USA

\section{SUBSCRIPTION INFORMATION}

Volume 1 (2006), 4 issues per year

Print ISSN: 1748-9237 Online ISSN: 1748-9245

Individual rate: $£ 76.00 / U S \$ 141.00$

Institutional rate: $£ 235.00 /$ US $\$ 435.00$

Online-only institutional rate: $£ 199.00 / U S \$ 367.00$

For special $\mathrm{IOM}^{3}$ member rates please email

subscriptions@maney.co.uk

\section{For further information or to subscribe online please visit www.maney.co.uk}



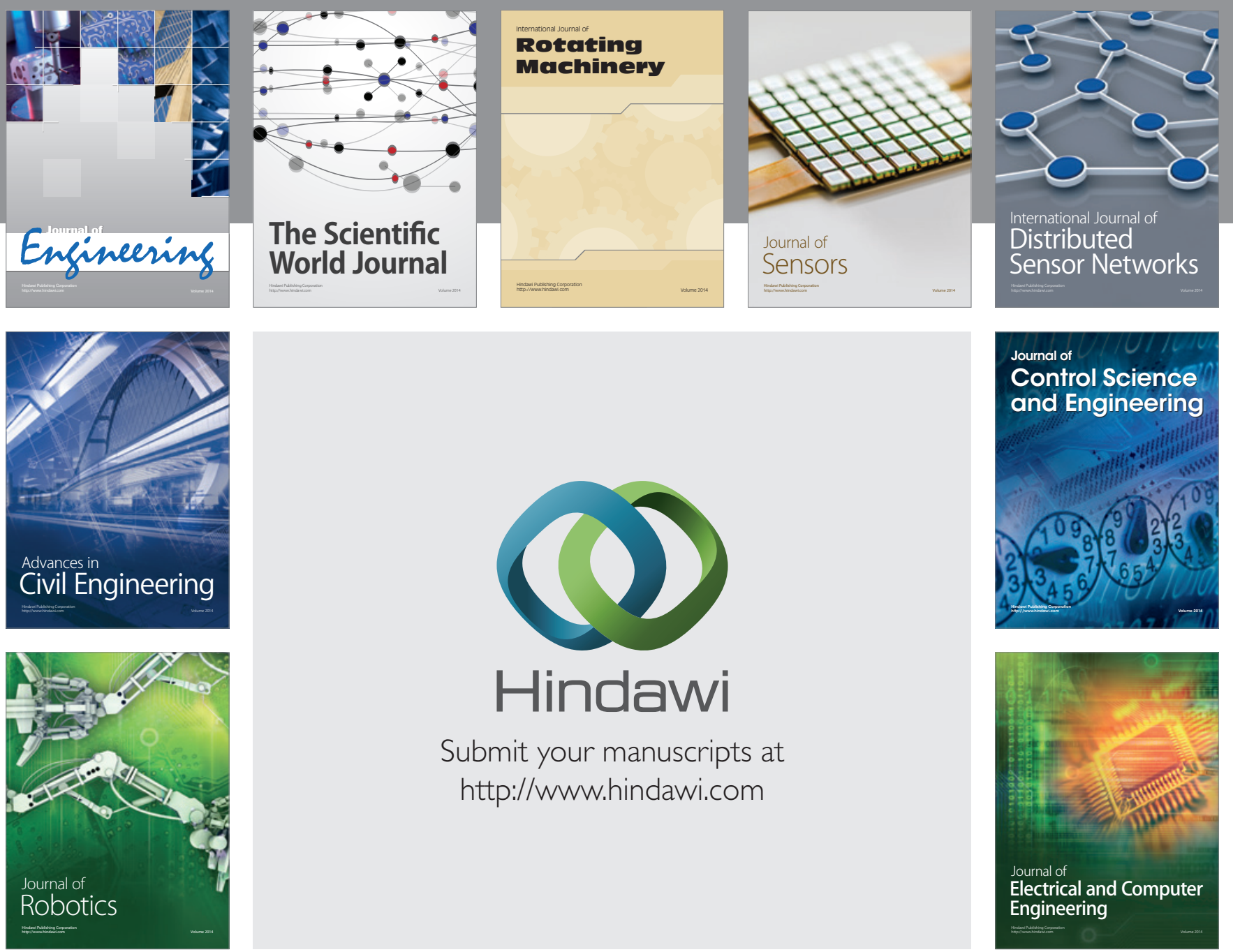

Submit your manuscripts at

http://www.hindawi.com
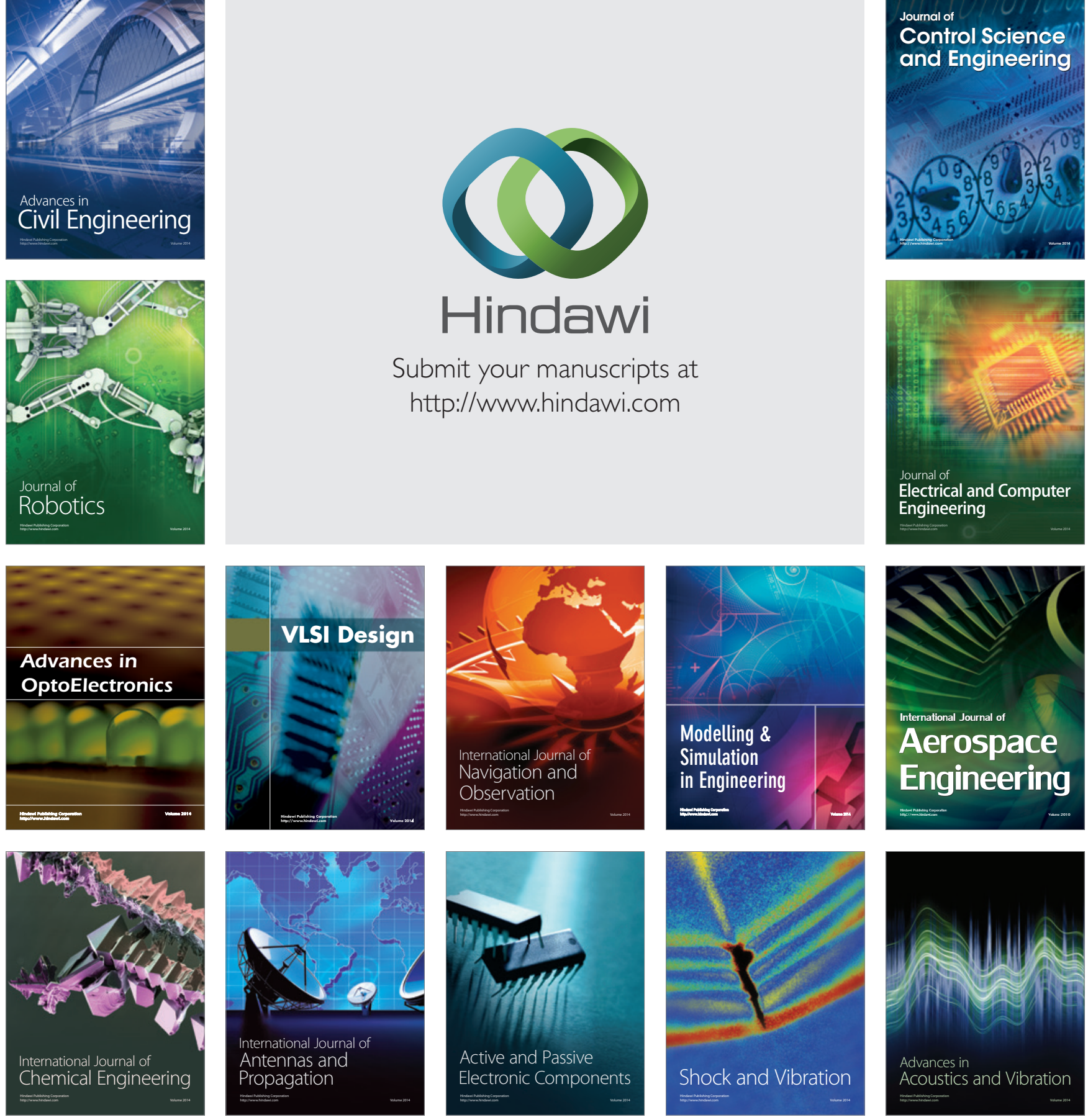